\title{
LAS ESPADAS DE HIERRO DE LA NECRÓPOLIS DE SON PELLISSER; AVANCE PRELIMINAR
}

\author{
THE IRON SWORDS FROM THE NECROPOLIS OF SON PELLISSER; \\ PRELIMINARY ADVANCE
}

POR

\author{
Agustín Fernández Mártinez y Mercedes Alvarez Jurado-Figueroa**
}

\section{RESUMEN - ABSTRACT}

Este trabajo presenta las espadas de hierro procedentes de la necrópolis de Son Pellisser (Calviá-Mallorca). Aunque el número de materiales recuperados es elevado y continúan en fase de estudio ofrecemos un avance preliminar sobre tres espadas de importación, localizadas entre los ajuares, así como su posible origen y vía de introducción en la isla. Estas armas constituirían la primera evidencia arqueológica de la participación de mercenarios baleáricos en las Guerras de Sicilia, entre cartagineses y griegos, desde el siglo V a. n. e.

This paper submits the iron swords from the necropolis of Son Pellisser (Calvià-Majorca). Although the materials that we find are numerous and still under research offer a preliminary study about three imported swords, found in burial objects, also their possible origin and way of introduction on the island. These weapons could be the first archaeological evidence that the Balearic mercenaries participated in the Wars of Sicily, between Carthaginians and Greeks, from the fifth century BC.

\section{Palabras Clave - Keywords}

Necrópolis; enterramientos en cueva; falcata; machaira; xiphos; mercenarios baleáricos; púnicos; Segunda Edad del Hierro; Mallorca; Islas Baleares.

Necropolis; cave burials; falcata; machaira; xiphos sword; Balearic mercenaries; Punic; Second Iron Age; Majorca; Balearic Islands.

\section{INTRODUCCIÓN}

La necrópolis de Son Pellisser se encuentra en el interior de una cueva natural, a unos 400 m de altura s. n. m., situada al SO de la Sierra de Na Burguesa (Calviá, Mallorca) en las Islas Baleares (fig. 1). La entrada a la cavidad está orientada hacia el NO en una zona de pronunciada pendiente que presenta un amplio dominio visual sobre el valle de Calviá. Tiene un desarrollo de 50 metros y consta de cuatro salas. Las salas 1 y 2 contenían restos arqueológicos, aunque se intervino en ambas, sólo en la primera se documentaron enterramientos en cal.

\footnotetext{
*Arqueólogo, agustinfernandez.arq@gmail.com, http://orcid.org/0000-0002-0121-1390

** CEFYP, arqueoinsula@gmail.com, http://orcid.org/0000-0003-2872-4900
} 
Desde época talayótica la cavidad se utiliza como necrópolis hasta que el derrumbe de la techumbre supone la imposibilidad de continuar con su uso y se abandona a principios del s. IV a. n. e. Este acontecimiento ha preservado el yacimiento de saqueos y alteraciones, haciendo posible que su estado fuera excepcional.

Los trabajos de campo se realizaron durante 2012, el objetivo principal de la intervención programada era dar respuesta a los numerosos interrogantes que aún hay sobre las necrópolis en cueva natural de Mallorca, los rituales funerarios y establecer su cronología.

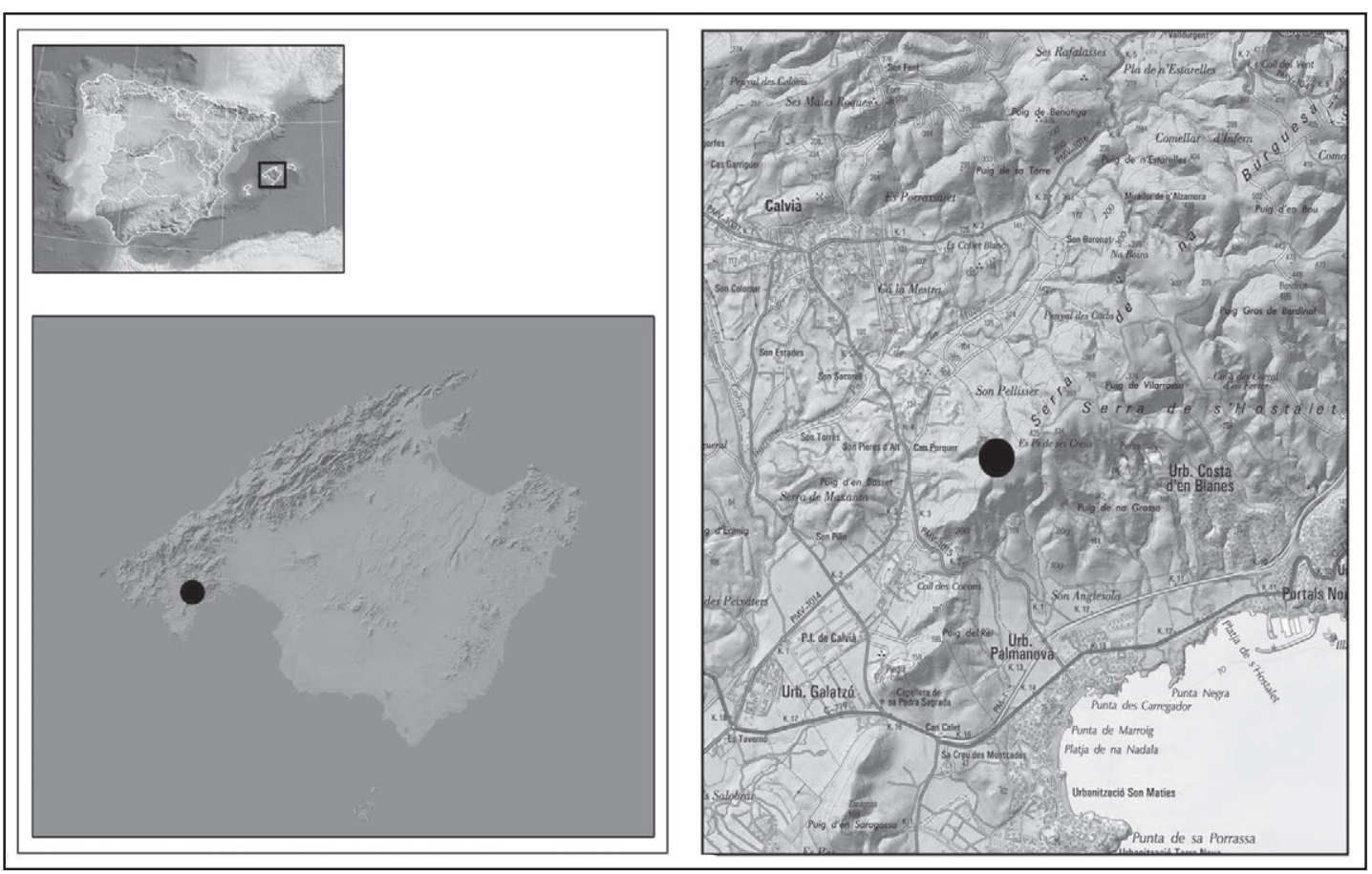

Figura 1. Localización geográfica y situación del yacimiento de Son Pellisser (Calvià, Mallorca).

\section{CONTEXTO ARQUEOLÓGICO: LOS ENTERRAMIENTOS EN CAL}

La secuencia de ocupación de esta cueva natural abarca desde finales del III milenio a. n. e. hasta principios del s. IV a. n. e. (Strydonck et alii, s. f.) ${ }^{1}$. Los niveles más antiguos corresponden a un uso de estabulación o pastoreo estacional, durante el período talayótico se realizan algunas inhumaciones hasta que a inicios del postalayótico comienzan a practicarse y se extienden los enterramientos en cal.

En muchas necrópolis en el interior de cuevas naturales de Mallorca y Menorca se documenta este tipo de ritual funerario, practicado durante la Protohistoria, que presenta variantes. Esta práctica ha dado lugar en los niveles estratigráficos correspondientes a unos depósitos

1 Para establecer la secuencia cronológica del yacimiento se ha realizado un programa de dataciones radiocarbónicas, dirigido por M. van Strydonck en colaboración con el Institut Royal du Patrimoine Artistique de Bruselas, a partir de muestras (sobre distintos tipos de materia orgánica) de los distintos niveles estratigráficos y posterior análisis estadístico Bayesiano. Los resultados están pendientes de publicar. 
blanquecinos muy característicos formados por los restos óseos, sus ajuares funerarios, roca caliza y el conjunto de procesos postdeposicionales que los han afectado ${ }^{2}$.

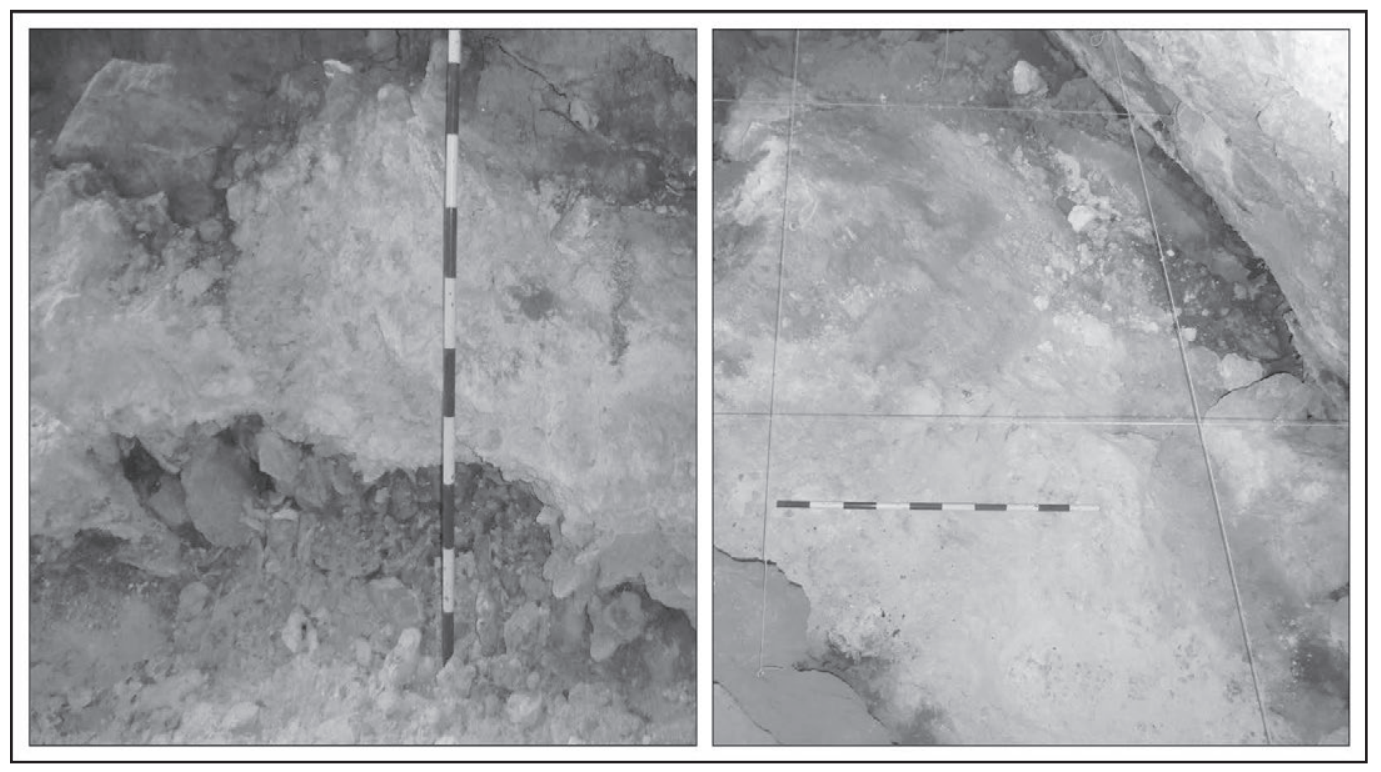

Figura 2. Nivel de enterramientos en cal, necrópolis de Son Pellisser, vista de perfil y planta.

Las armas objeto del presente estudio se localizaron en la Sala 1 (fig. 2), en niveles de enterramiento en cal. En esta etapa la cavidad fue utilizada exclusivamente como necrópolis, albergando un número importante de restos humanos y ajuares funerarios. En dicha fase coexisten inhumaciones primarias y secundarias, tanto individuales como múltiples, que no guardan un patrón regular en cuanto a posición y orientación. También aparecen cremaciones y distintos signos de termoalteración en los restos óseos.

En la necrópolis se han documentado individuos de todas las edades y ambos sexos, acompañados de uno o varios objetos; la mayoría podrían haber sido de uso personal (espiraliformes, agujas) y algunos solamente con carácter ritual como los tintinnabula (Alvarez y Fernández, 2015).

\section{EL ARMAMENTO}

Entre los ajuares funerarios se localizaron una veintena de armas de hierro ${ }^{3}$; la mayor parte cuchillos y un regatón actualmente en fase de estudio. Otra pequeña parte está formada por tres espadas de importación. No se han documentado armas defensivas ${ }^{4}$.

2 Por ejemplo; el proceso de cementación producido por calcita de precipitación química.

3 Estas armas, a pesar de formar parte de los ajuares y llevar implícita una fuerte carga ritual o apotropaica, consideramos que fueron creadas para la guerra y en un momento anterior a ser depositadas en la necrópolis cumplieron esa función (Gabaldón, 2010:192). Al tratarse de un avance preliminar, por el momento, evitamos lanzar hipótesis sobre el carácter simbólico de estas armas y el ritual de enterramiento.

4 Se localizaron pequeños fragmentos de un disco de metal, de base cobre, no descartamos que pudiera tratarse de un umbo aunque el mal estado de conservación hace imposible una identificación correcta (ver fig. 19, al final del texto). 
Las tareas de estabilización y conservación preventiva de las armas fueron complicadas debido al estado en que se localizaron ${ }^{5}$ (fig. 3). El grado de conservación de los materiales, en general, era deficiente debido a: termoalteraciones, acción del carbonato cálcico, filtraciones de agua, presión sedimentaria. Tras estabilizarlas se procedió al estudio de las piezas, estableciendo su clasificación tipológica, principalmente a partir de Quesada (1992 y 1997).

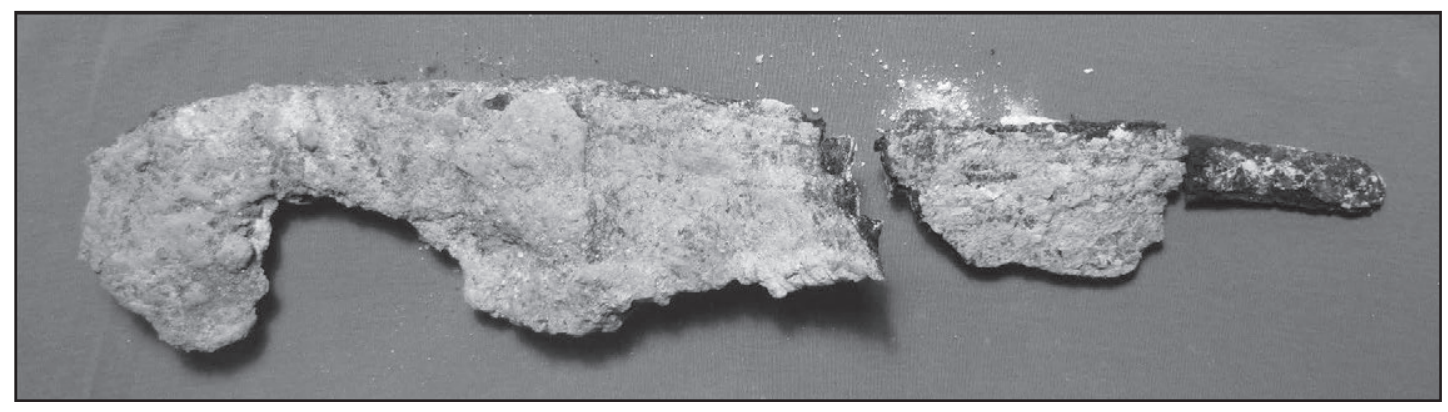

Figura 3. Estado en que fue localizada la falcata.

No se han realizado pruebas de laboratorio, que pudieran suponer un peligro o pérdida de material a las piezas, ya que el análisis de visu fue suficiente para determinar que su procedencia era alóctona por su tipología y tecnología de fabricación, sin paralelos conocidos en la isla. Los resultados del estudio se exponen a continuación.

\section{III.1. ARMAS OFENSIVAS}

\section{III.1.1. Machaira itálica}

La machaira se encuentra prácticamente completa conservando gran parte de la empuñadura y casi toda la hoja, de la que falta solamente parte de la punta (fig. 4). A pesar de la pérdida de materia, la ligera deformación de la hoja y a los efectos de la oxidación, podemos calificar la conservación de la pieza como buena, tomando para la valoración del estado de conservación del arma los criterios de descripción utilizados por Quesada (1997: 84).

Forjada en hierro, parece estar formada por tres láminas de metal, la central más gruesa que las exteriores. De la empuñadura sólo se conserva la parte correspondiente a la lengüeta que es de forma rectangular y aristas ligeramente redondeadas. Se contabilizan cinco remaches de hierro cuadrados, en ambas caras, para la sujeción de las cachas (dos en la parte de la guarda basal y tres en la lengüeta) que probablemente eran de materia orgánica ya que no han dejado huella en el registro arqueológico (fig. 5).

La hoja va adoptando una forma curvada desde el arranque de la empuñadura. Presenta un filo principal en forma de "S" muy abierto cóncavo-convexo. El filo tajante no comienza en la base de la empuñadura si no desde la parte convexa del filo. El grosor del dorso de la hoja se mantiene prácticamente constante en todo su recorrido y va decreciendo a partir de su tercio distal. Una acanaladura, de fondo redondeado, discurre paralela al dorso de la hoja desde la

\footnotetext{
5 Agradecemos a nuestra conservadora-restauradora (Delia Eguíluz Maestro) el gran trabajo realizado, en parte subvencionado con fondos de Cultura, Patrimonio y Deportes del Consejo Insular de Mallorca.
} 


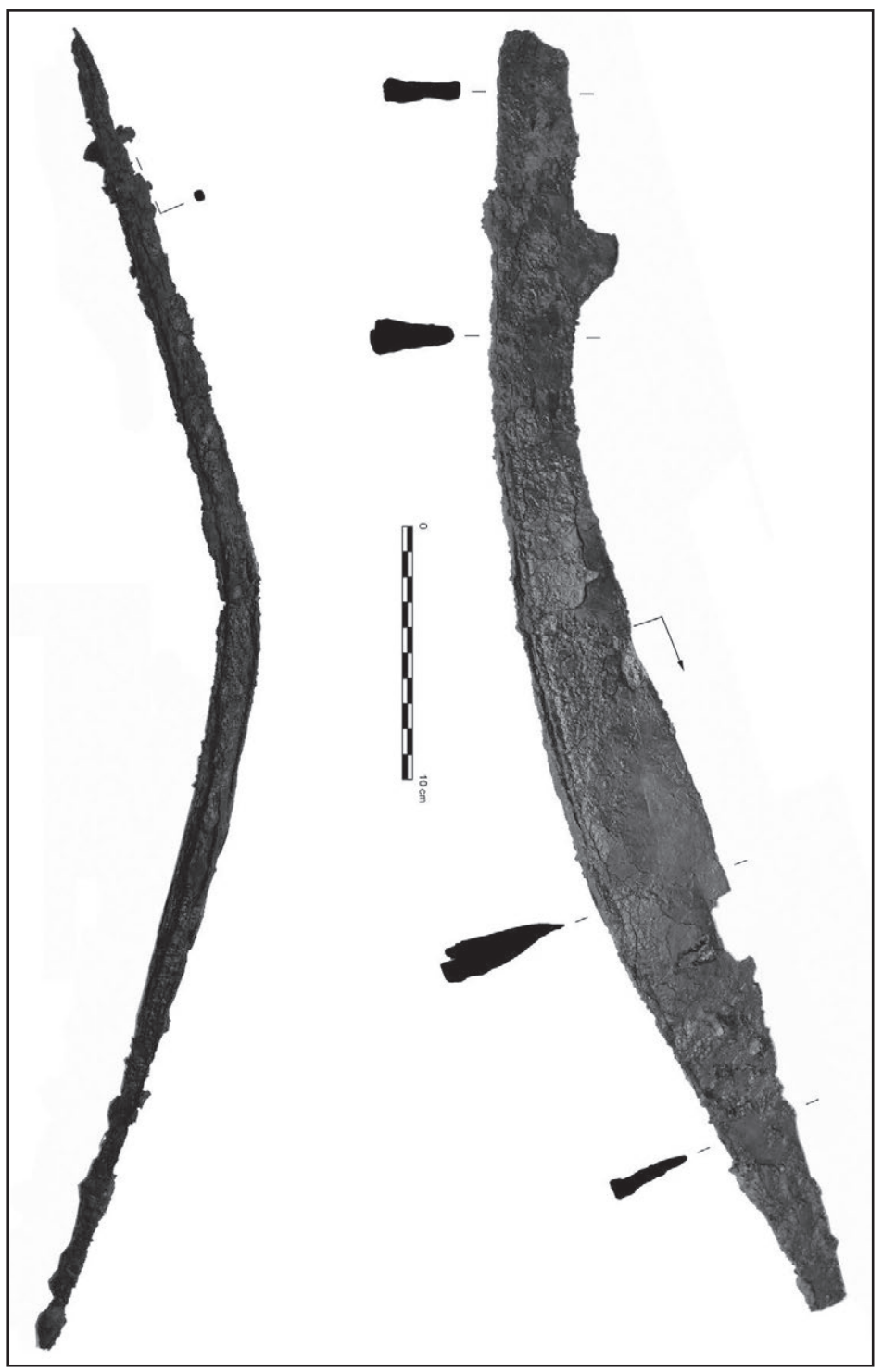

Figura 4. Vistas machaira itálica procedente de necrópolis de Son Pellisser. Museo de Mallorca (NI: DA12/06-14-132).

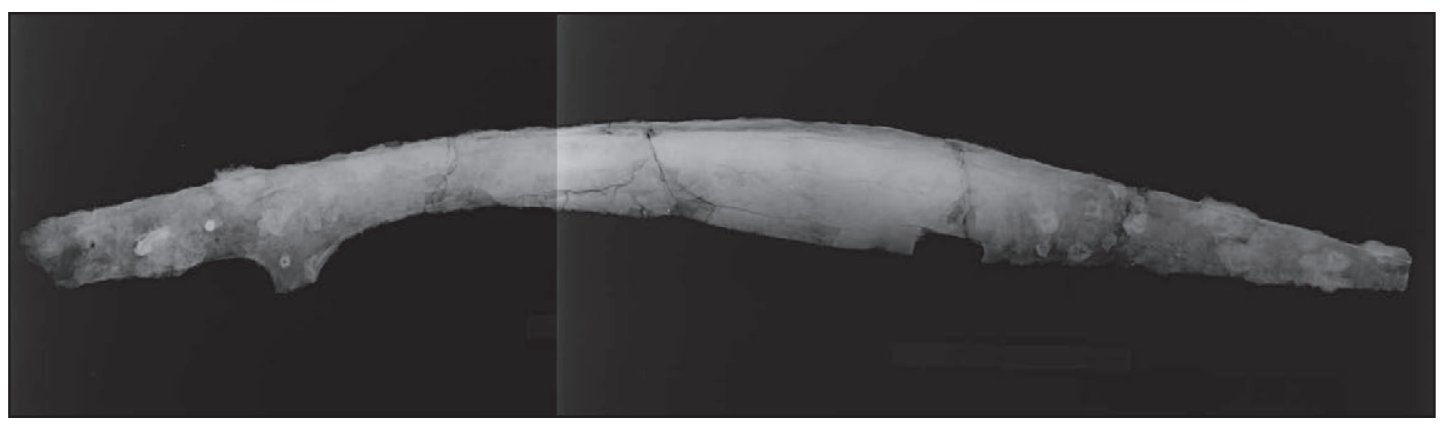

Figura 5. Imagen radiográfica machaira necrópolis de Son Pellisser. 
empuñadura llegando casi al final de la hoja que posee una sección en "T" (fig. 6). La pieza no presenta signos de inutilización intencionada ${ }^{6}$.

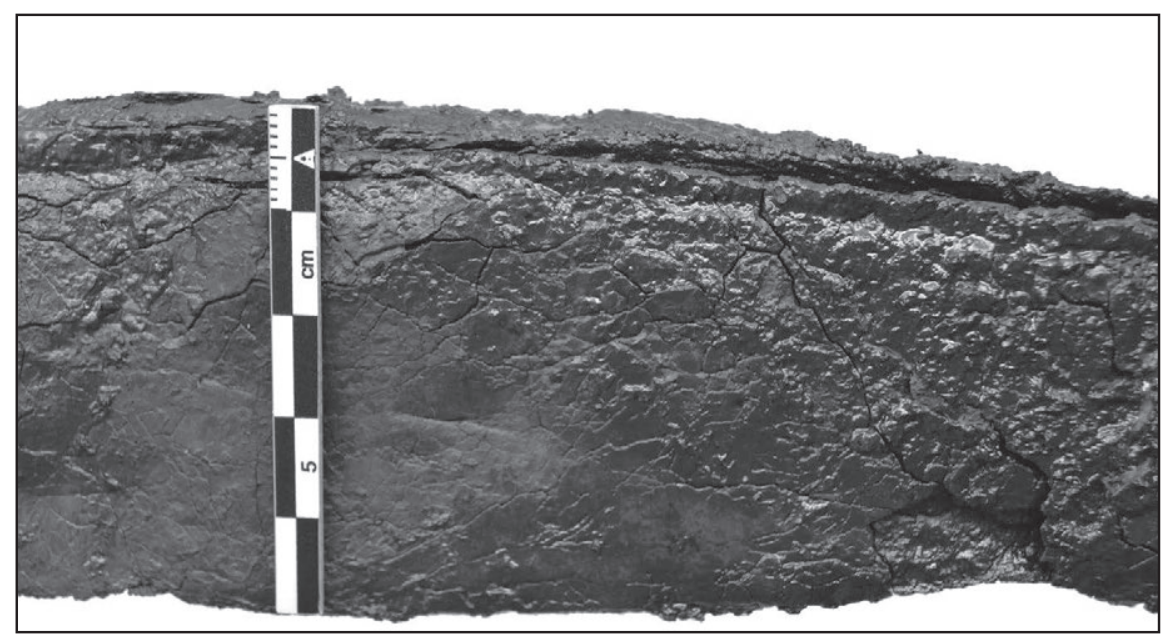

Figura 6. Detalle acanaladura machaira.

Las dimensiones del arma son: longitud máxima (conservada) $57.2 \mathrm{~cm}$; longitud de la hoja (conservada) $46 \mathrm{~cm}$; anchura máxima de la hoja $5.1 \mathrm{~cm}$; anchura mínima de la hoja $3.1 \mathrm{~cm}$; grosor máximo de la hoja $1.3 \mathrm{~cm}$; longitud empuñadura (conservada) $11.2 \mathrm{~cm}$; grosor máximo de la empuñadura $0.8 \mathrm{~cm}$; anchura basal $4.9 \mathrm{~cm}$; ángulo axial $72^{\circ}$. Se estima que la longitud aproximada del arma era de $65 \mathrm{~cm}$.

El nivel arqueológico del que procede esta espada lo situamos claramente en la primera mitad del s. V a. n. e. a partir de la secuencia estratigráfica y fechas radiocarbónicas obtenidas (vid supra ${ }^{1}$ ).

Los estudios sobre las machairas grecoitálicas han sido abordados por diversos investigadores como Cabré, Stary, Quesada o Cherici (2003). Las características morfológicas o tipología de esta machaira, procedente de la necrópolis de Son Pellisser, nos llevan a clasificarla como del tipo itálico (Quesada, 1997: 131-132, 150-151). Una de las principales razones de esta clasificación

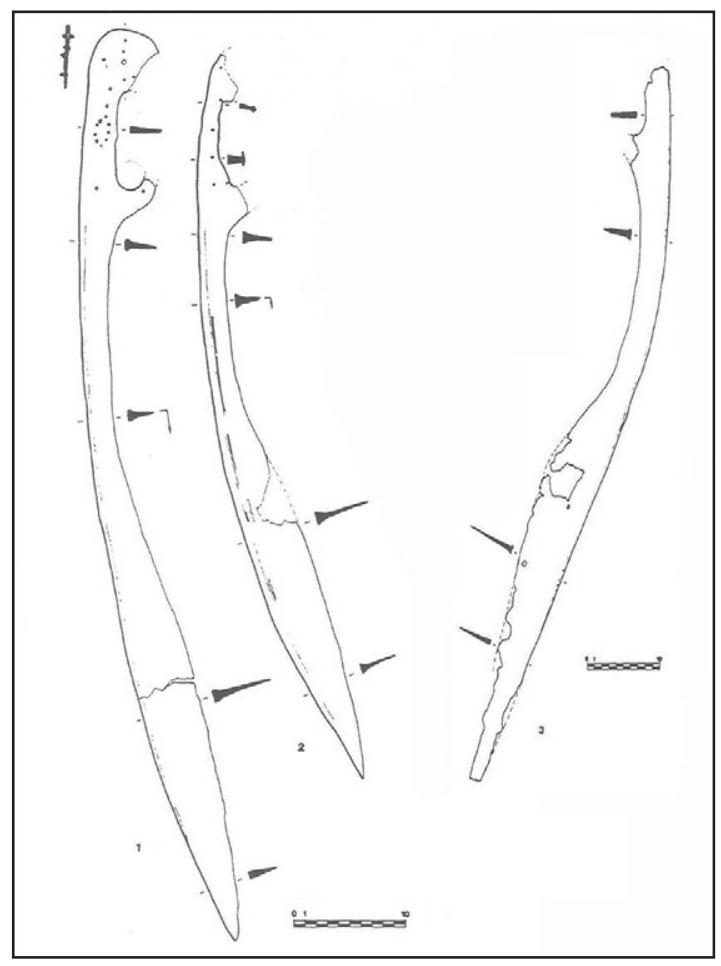

Figura 7. Espadas itálicas: 1 y 2) procedentes de Gualdo Tadino; 3) de Elche (Quesada, 1997).

6 La muesca que se observa en el filo de la hoja es una pérdida de materia postdeposicional no una inutilización intencionada del arma. 
es por la forma de su dorso; las de tipo itálico presentan el dorso muy curvado, al contrario de las griegas que presentan un dorso recto. Los paralelos que encontramos son numerosos y provienen principalmente de piezas halladas en la Península Itálica, Córcega, Sicilia y Península Ibérica. Podemos citar algunos ejemplos como las espadas itálicas procedentes de la necrópolis de Gualdo Tadino y Bomarzo (Quesada, 1997: 131) o la localizada en Elche (fig. 7).

\section{III.1.2. Xiphos}

La espada se conserva fragmentada en dos partes y doblada, aunque prácticamente completa. Las pérdidas de materia se localizan principalmente en la empuñadura y la hoja. La conservación de la pieza puede calificarse como regular (fig. 8).

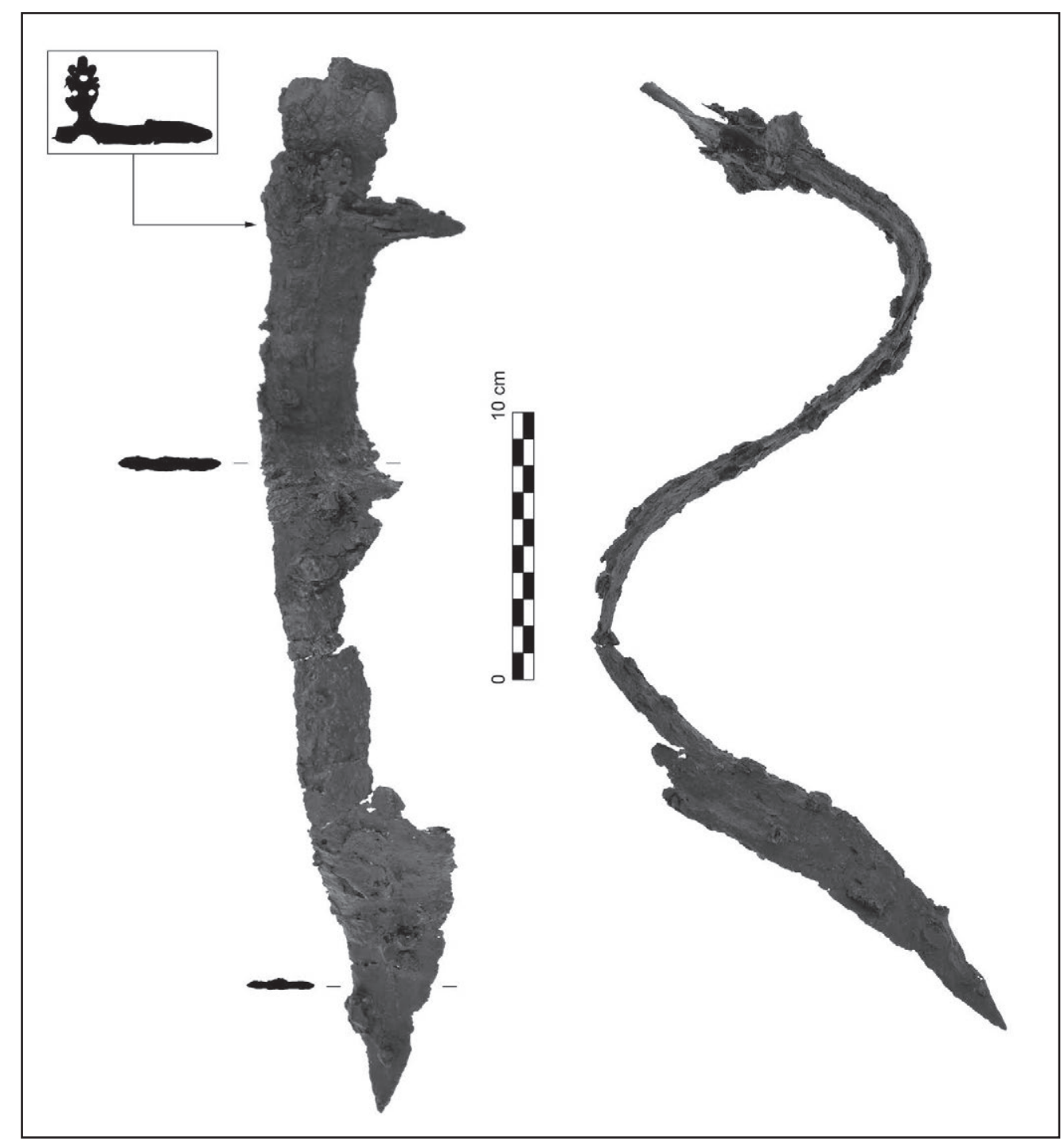

Figura 8. Vistas xiphos procedente de la necrópolis de Son Pellisser. Museo de Mallorca (NI: DA12/06-14-91). 
La empuñadura conserva sólo una parte de la lengüeta plana. La guarda aparece con unas aletas desarrolladas y sobre ella se proyecta una lámina de hierro, sujeta con remaches, que presenta escotadura semicircular en la base. En la parte superior de la guarda sobresale una palmeta estilizada y sobre ella se observan tres perforaciones que posiblemente servirían para el engarce de algún tipo de remate (fig. 9).

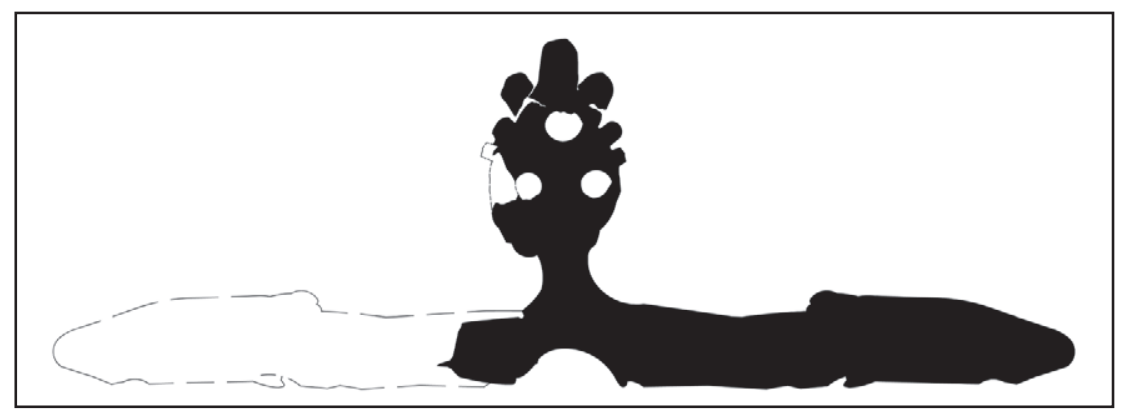

Figura 9. Reconstrucción decoración empuñadura xiphos de Son Pellisser

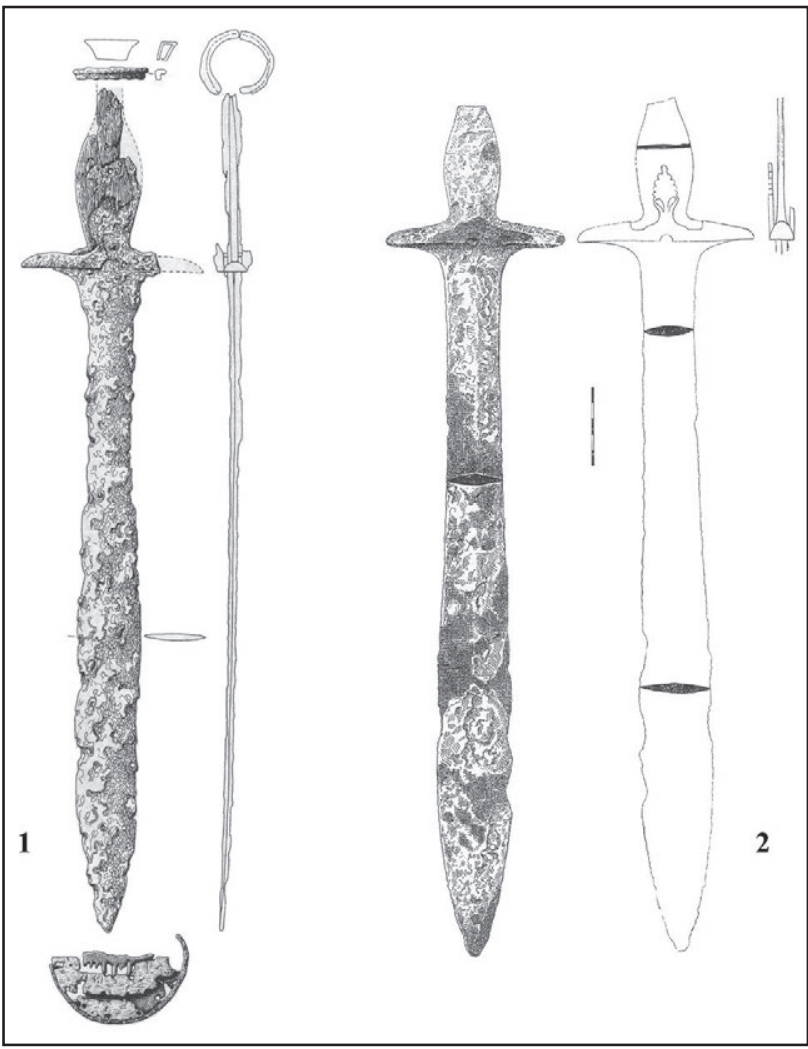

Figura 10. Espadas griegas localizadas en otras necrópolis: 1) procedente de Vitsa (Dirlmeier, 1993) y 2) de Zimnicea (Alexandrescu, 1980).
La hoja presenta doble filo, que converge en la punta, y nervio central. Es ligeramente pistiliforme y sobre ella discurren dos acanaladuras de fondo curvado. La sección de la hoja tiene una forma levemente ondulada. La pieza no presenta signos de inutilización intencionada ${ }^{7}$.

Las dimensiones del arma son: longitud máxima (conservada) 50 $\mathrm{cm}$; longitud de la hoja $44 \mathrm{~cm}$; anchura máxima de la hoja $3.9 \mathrm{~cm}$; anchura mínima de la hoja (parte proximal) $3.4 \mathrm{~cm}$; grosor máximo de la hoja $0.6 \mathrm{~cm}$; longitud empuñadura (conservada) $6 \mathrm{~cm}$; grosor máximo de la empuñadura $0.17 \mathrm{~cm}$. Se estima que la longitud aproximada del arma era de $55 \mathrm{~cm}$.

El nivel arqueológico, del que procede esta pieza, lo hemos situado en la segunda mitad del s. V a. n. e. a partir de la secuencia estratigráfica y fechas radiocarbónicas obtenidas.

La espada xiphos es un tipo de arma de origen griego. Los hallazgos

7 La deformación que se observa en el arma es debida a procesos tafonómicos que le han afectado, no fue inutilizada intencionalmente. 
son numerosos y concentrados básicamente en Grecia y la Península Itálica. Se conocen ejemplos similares, a la espada de Son Pellisser, de las necrópolis griegas de Philia y Vitsa (KilianDirlmeier, 1993: láms. 55 a 57), las italianas de Offida y Alfedena (Stary, 1981: Anexos 8 y 9) o el yacimiento de Zagortsi en Bulgaria (Nankov, 2007: 40, fig. 2). El ejemplar con mayores paralelos fue hallado en la necrópolis de Zimnicea (Rumanía) (Alexandrescu, 1980: 108, fig. 60) (fig. 10).

\section{III.1.3. Falcata}

La falcata recuperada se encuentra incompleta conservando casi toda la empuñadura y parte de la hoja (fig. 11). A consecuencia de las alteraciones del hierro, pérdida de materia y procesos que han actuado sobre el arma como la presión y desplazamiento de los sedimentos, calificamos la conservación de la pieza como regular.

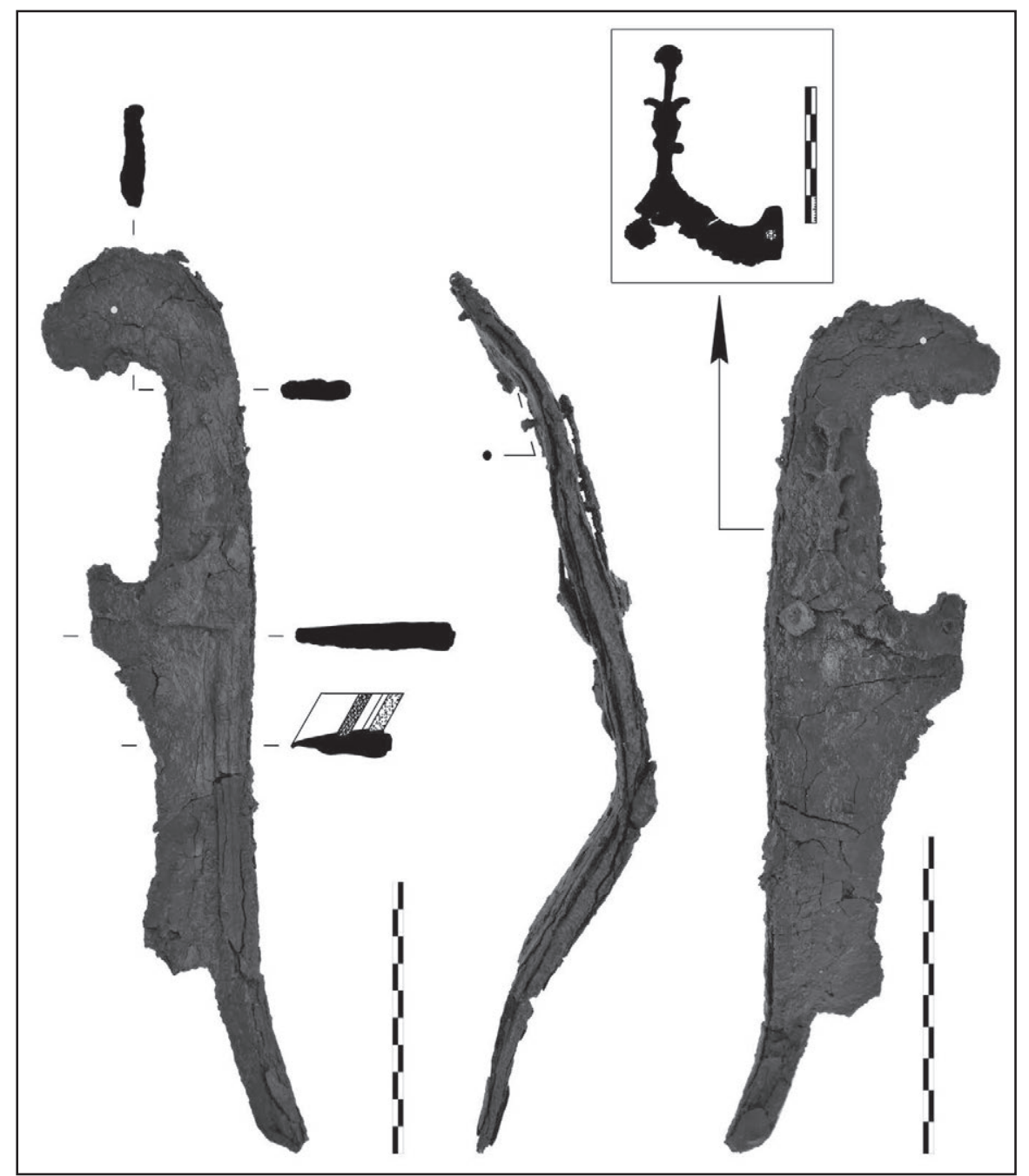

Figura 11. Vistas falcata procedente de la necrópolis de Son Pellisser. Museo de Mallorca (NI: DA12/06-14-20). 
En cuanto a la forma de la empuñadura; su adscripción a alguno de los dos tipos conoci$\operatorname{dos}^{8}$, con cabeza de caballo o ave, es problemática porque a pesar de las alteraciones del hierro se observan características propias. No es posible determinar si la guarda lateral era maciza o de cadenilla al haber desaparecido este elemento. Se aprecian seis remaches redondos de hierro, por cada cara, más uno de bronce localizado en el pomo de la empuñadura que cumpliría una función decorativa (simulando el ojo del animal). Los remaches aparecen repartidos entre la lengüeta y el pomo para la sujeción de las cachas, de algún material orgánico que no se ha conservado en el registro (fig. 12).

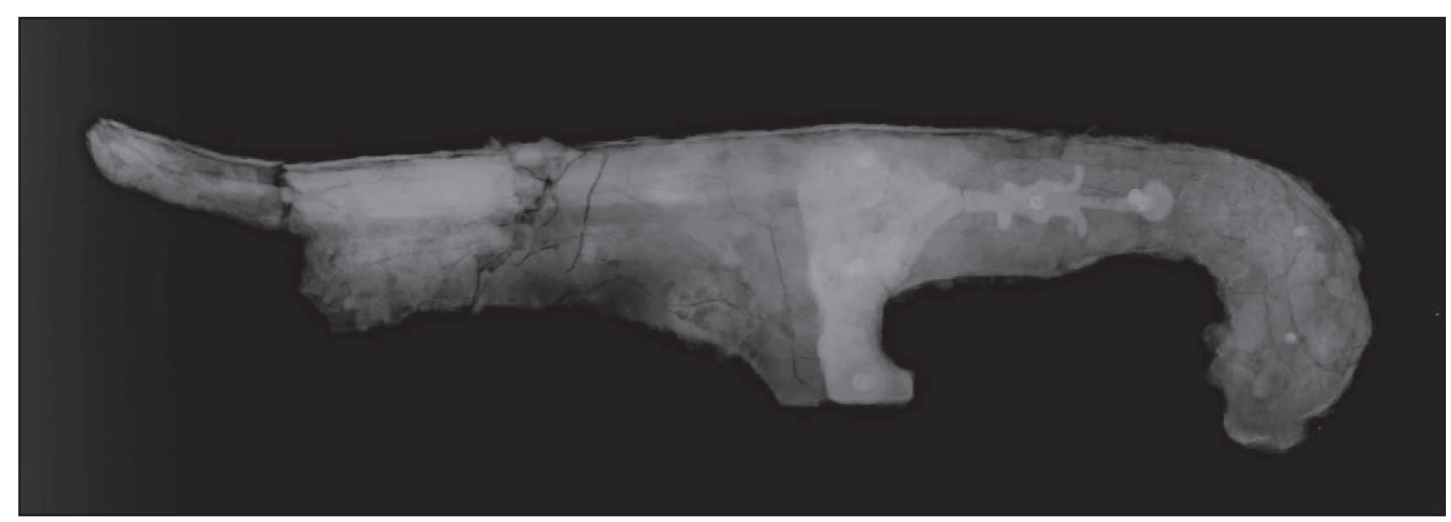

Figura 12. Imagen radiográfica falcata necrópolis de Son Pellisser.

La guarda basal está formada por una fina lámina de metal. De la cartela surge un elemento decorativo ocupando gran parte de la espiga. El espacio que separa esta cartela desarrollada y la lengüeta es de $3 \mathrm{~mm}$, estando provista de cinco remaches para la sujeción de las cachas (fig. 13).

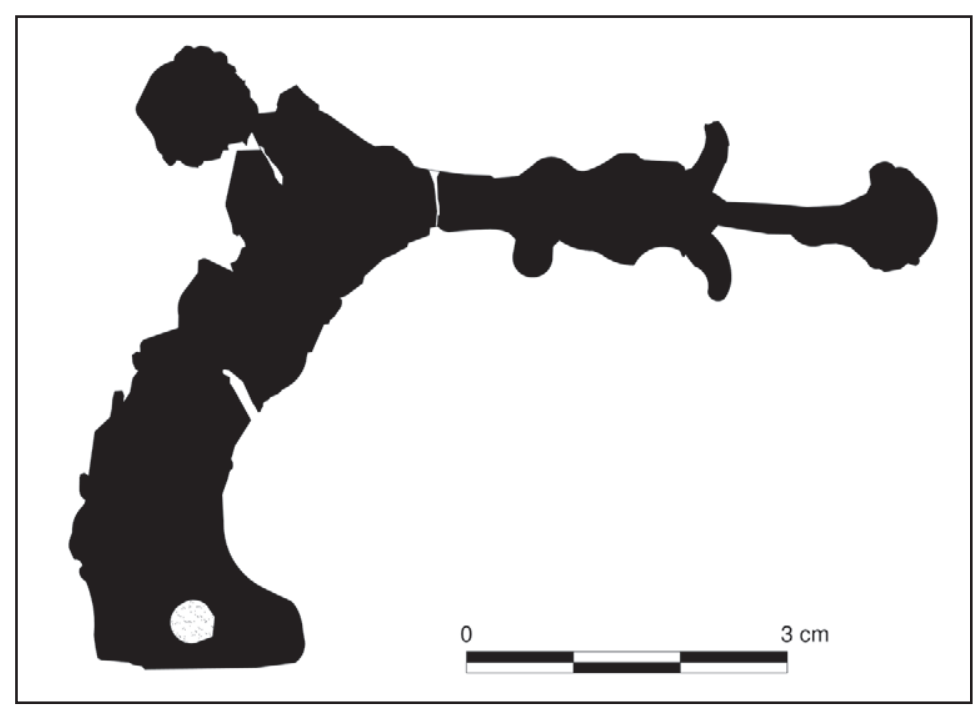

Figura 13. Detalle guarda basal y cartela, falcata de Son Pellisser.

8 Quesada, 1997: 100; Cuadrado, 1989: 15 
La hoja presenta un filo principal, que arranca desde la base de la empuñadura, de perfil cóncavo-convexo. Sobre la hoja conservada se pueden observar claramente (en una de las caras) dos acanaladuras que discurren paralelas al dorso, arrancan de la empuñadura y recorren toda la hoja. La primera acanaladura más próxima al dorso de la hoja tiene una sección en forma de "L" con fondo plano, la segunda es ancha con una profundidad de $1.5 \mathrm{~mm}$ y fondo plano, tipo A (Quesada, 1988: 276) (fig. 14). En la parte conservada no presenta signos de inutilización intencionada.

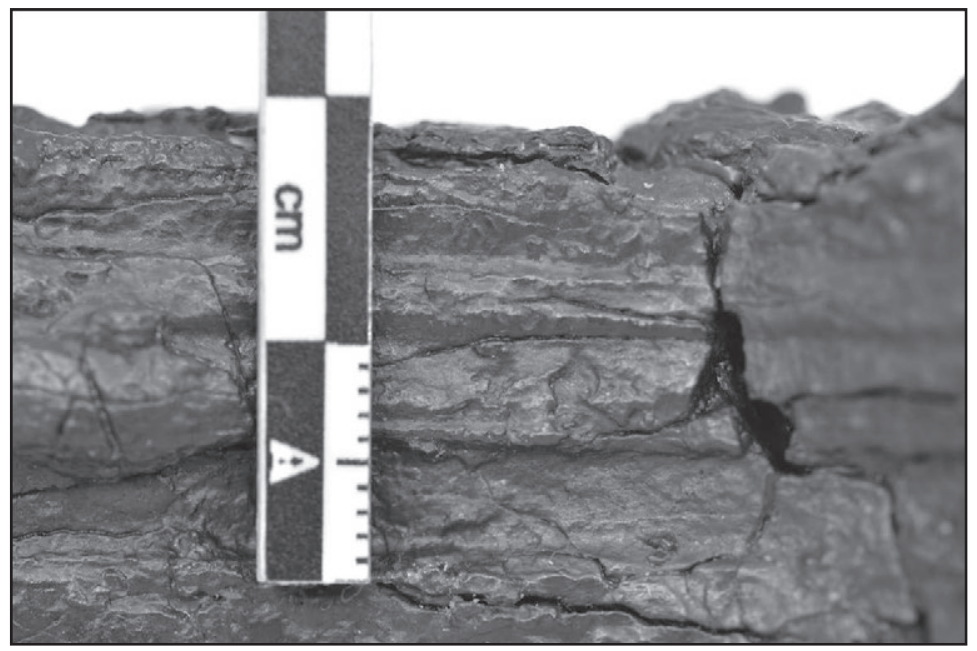

Figura 14. Detalle acanaladuras falcata.

Las dimensiones del arma son las siguientes: longitud máxima (conservada) $32.4 \mathrm{~cm}$; longitud de la hoja (conservada): $20.2 \mathrm{~cm}$; longitud empuñadura $12 \mathrm{~cm}$; longitud interior de la empuñadura (LIE) $7.6 \mathrm{~cm}$; anchura mínima de la hoja $3.4 \mathrm{~cm}$; anchura basal $5.9 \mathrm{~cm}$. A pesar de no conservarse completa estimamos que la longitud total del arma sería de unos $60 \mathrm{~cm}$, dentro de las medidas conocidas para este tipo de arma (Quesada, 1997: 85-86) (fig. 15).

El nivel arqueológico, del que procede esta pieza, lo hemos situado a finales del s. V a. n. e. a partir de la secuencia estratigráfica y fechas radiocarbónicas obtenidas99.

\begin{tabular}{|c|c|c|}
\hline & Falcata de Son Pellisser $(\mathrm{cm})$ & Media de medidas $^{1}(\mathrm{~cm})$ \\
\hline Long. Máx. & $60($ estim.) & 60.18 \\
\hline Long. Hoja & $48($ estim.) & 48.88 \\
\hline Long. F.D. & ----- & 23.96 \\
\hline Long. Empuñ. & 12 & 11 \\
\hline L.I.E. & 7.6 & 7.99 \\
\hline Anch. Máx Hj & ---- & 5.84 \\
\hline Anch. Mín. Hj & 3.4 & 3.75 \\
\hline Anch. Basal & 5.9 & 6.43 \\
\hline Ángulo Axial & ----- & 74.26 \\
\hline
\end{tabular}

Figura 15. Cuadro de dimensiones y medidas

\footnotetext{
9 En ningún caso puede ser posterior al desplome del techo y visera de la cueva, hecho que motivó el abandono de la necrópolis, entre 420-370 a. n. e. según nuestros datos (vid supra ${ }^{1}$ ).
} 
El carácter artesanal de este tipo de armas y algunas peculiaridades que presenta la pieza hace difícil determinar su procedencia. Sin embargo, posee características comunes con otras de la Península Ibérica estudiadas por diferentes autores (Cabré, 1934a y b; Cuadrado, 1989; Quesada, 1992 y 1997).

La falcata localizada en la necrópolis de Son Pellisser está realizada a partir de tres láminas de metal forjado, soldadas entre sí, la central más gruesa que las laterales (fig. 16). La ausencia de aproximadamente dos tercios de la hoja nos priva de una parte importante de información sobre las acanaladuras, aún así, podemos clasificarla dentro de la tipología 2I (Quesada, 1988: 276).

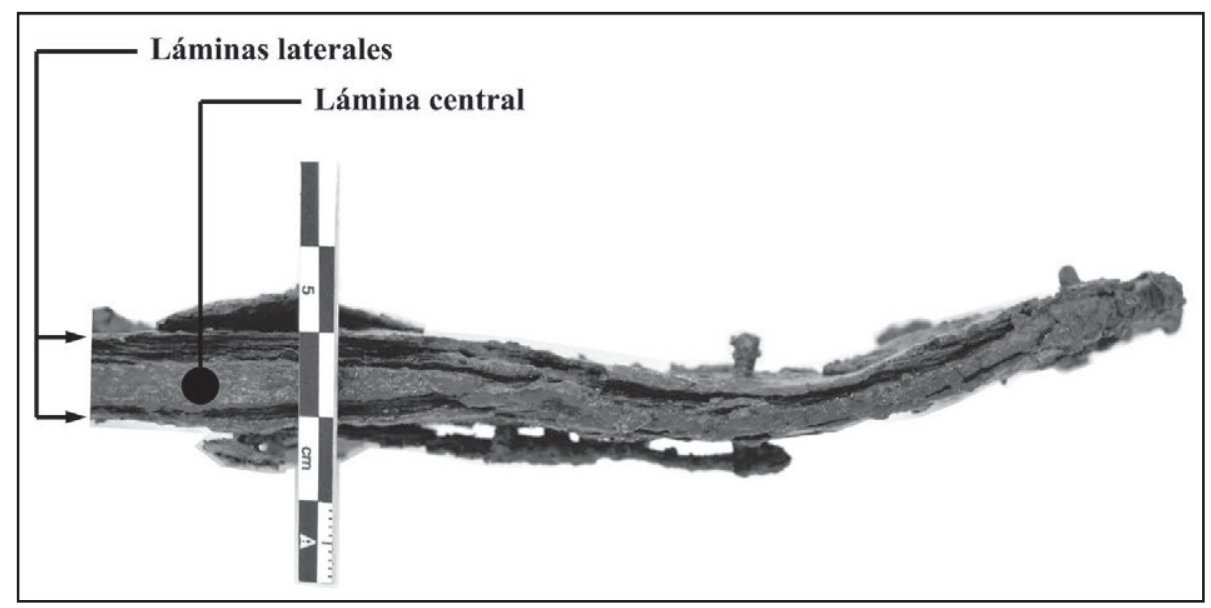

Figura 16. Láminas metal en detalle.

En la empuñadura, la lámina central va decreciendo desde la lengüeta hacia el pomo. Su decoración no tiene paralelos conocidos hasta el momento aunque algunos autores nos hablan de remates con forma de felino, en empuñaduras con cabeza de caballo (Quesada, 1997: 120). En cualquier caso, de representar un motivo zoomorfo, es similar a un felino (figs. 17 y 12).

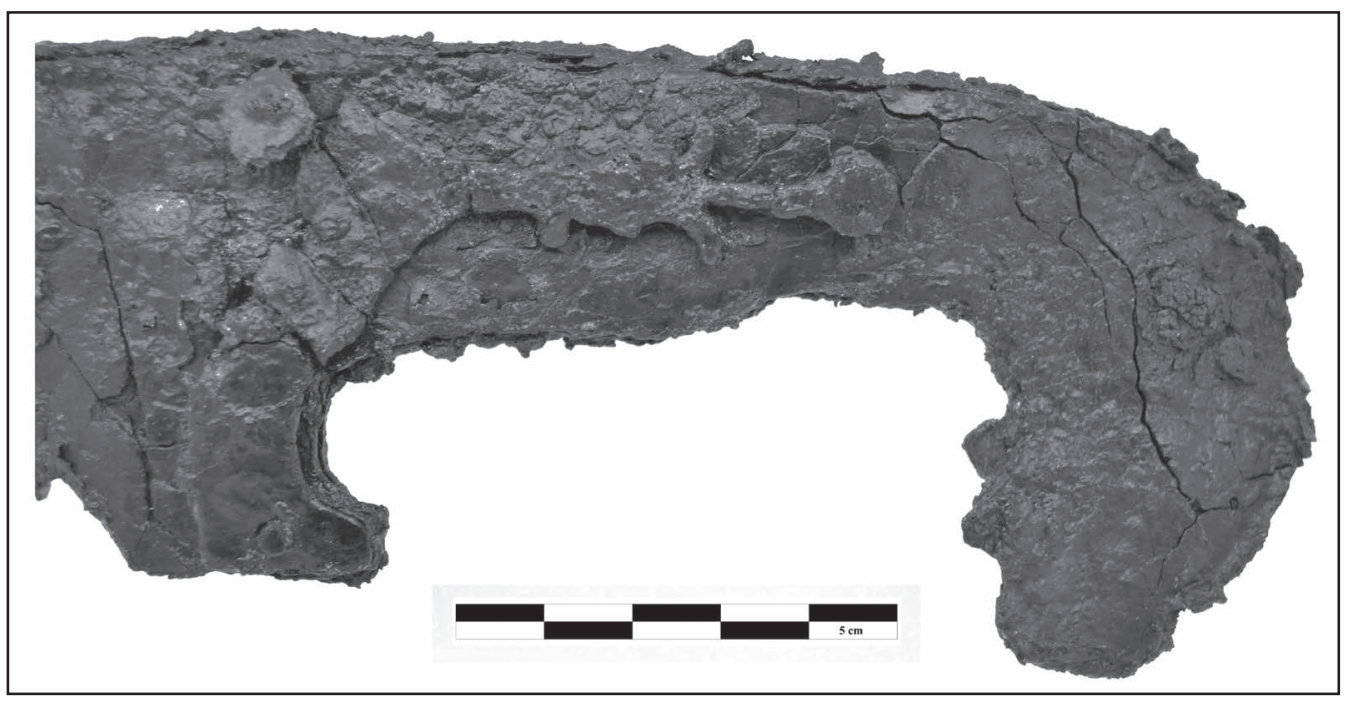

Figura 17. Detalle empuñadura falcata de Son Pellisser. 
A las decoraciones como la empuñadura con cabeza de animal, el remache de bronce simulando el ojo y las acanaladuras de la hoja habría que añadir la cartela desarrollada con elementos decorativos. A primera vista, la ornamentación representa motivos vegetales pero al observarla detenidamente parece imitar la empuñadura de algún tipo de espada o puñal de frontón como el procedente de Almedinilla (Quesada, 1999: 77) (figs. 12 y 18).

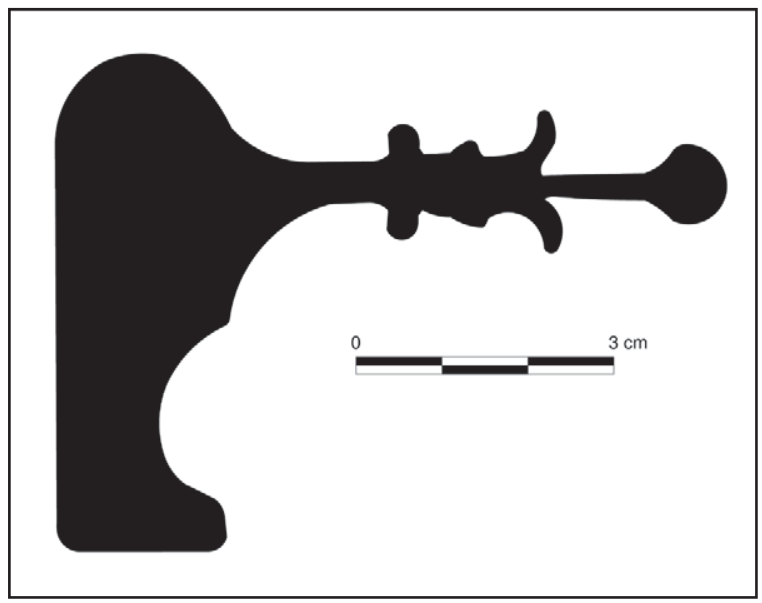

Figura 18. Reconstrucción guarda basal y decoración cartela falcata de Son Pellisser.

\section{DISCUSIÓN Y CONCLUSIONES PRELIMINARES}

Aunque el estudio de los materiales sigue en curso, hemos considerado de interés ofrecer un avance preliminar de estas armas por la trascendencia de los hallazgos. Esperamos que enriquezca la discusión científica, aportando nuevos datos sobre el armamento y mercenariado. En cualquier caso, es necesario continuar ampliando el conocimiento que tenemos sobre el fenómeno del mercenariado en Mallorca y de cómo afectó a la estructura socioeconómica del mundo talayótico. Igualmente profundizar en el papel de las Baleares en un contexto tan complicado como fue el Mediterráneo de los siglos VI al IV a. n. e.

Estas espadas fueron depositadas en la necrópolis con el objetivo de formar parte de los ajuares. Con independencia de las connotaciones ctónicas que poseen los enterramientos en cuevas naturales, del significado ritual que tienen estos objetos y de sus vinculaciones simbólicas con la guerra (Gabaldón, 2002-2003: 135), cuentan con todas las características formales y técnicas necesarias para haber tenido un carácter funcional antes de ser depositadas en la necrópolis. Ninguna de las armas apareció de forma individualizada, alejada de los enterramientos o en una posición diferente al resto de los objetos que acompañaban a los difuntos.

Entre los ajuares localizados en Son Pellisser hay una proporción mayoritaria de elementos personales que pudieron pertenecer al individuo en vida, si bien, se han documentado inhumaciones de recién nacidos que portan adornos personales. Esto da a entender que pasaron a pertenecerle postmortem con la función de acompañarlo en el más allá. Los restos óseos que se exhumaron con las espadas continúan en estudio; podemos avanzar que eran adultos y varón el inhumado junto a la xiphos.

El ritual funerario es una discusión no resuelta, de momento, pero es evidente el alejamiento de la tradición talayótica y sintomática la introducción de costumbres (como la cremación o 
acompañar al difunto de objetos) que se van extendiendo con el paso del tiempo. Todo apunta a que esta diversificación en los rituales funerarios se deba al contacto entre mercenarios baleáricos y otras gentes, durante los conflictos armados en que participaron, hecho que debió incidir en sus mentalidades (Guerrero, 1980).

La presencia de honderos o mercenarios baleáricos en los conflictos armados que citan las fuentes clásicas, entre cartagineses y griegos, es un acontecimiento ya analizado (Domínguez Monedero, 2005; Graells, 2014). Su participación en las Guerras de Sicilia podría explicar la fuerte influencia griega y púnica que registra la arqueología. El hallazgo de estas armas sería la evidencia arqueológica que vendría a confirmarlo.

Como posibles vías de introducción en Mallorca de estas piezas se plantean distintas hipótesis: 1) por medio del comercio con el exterior, 2) llegada de aportes de población alóctona y 3) adquisición del arma a través de actividad mercenaria. Descartamos que la vía de introducción de estas espadas en la isla sea un episodio comercial porque acompañaban a distintos individuos que se localizaron en tres sectores y niveles diferenciados de la necrópolis. Aunque la segunda hipótesis no podemos descartarla; los contextos de procedencia de las espadas nos remiten a las Guerras de Sicilia y a las gentes que allí combatieron durante el s. V a. n. e. La tercera opción sería la más lógica, teniendo en cuenta el contexto general de una sociedad en belicosidad creciente.

A modo de conclusión preliminar; estas armas probablemente llegaron a la isla junto con los que retornaron de las Guerras de Sicilia, adquiridas como botín de guerra, premio o fruto del intercambio, otorgando prestigio a su poseedor, constituyendo la prueba material de la participación de mercenarios baleáricos en los conflictos armados entre cartagineses y griegos, y también de su regreso

Otra cuestión, en la que no todos los investigadores están de acuerdo, es el grado de jerarquización de la sociedad baleárica durante el postalayótico. En Son Pellisser observamos una inquietud creciente por acompañar a los difuntos con signos de ostentación aunque la disposi-

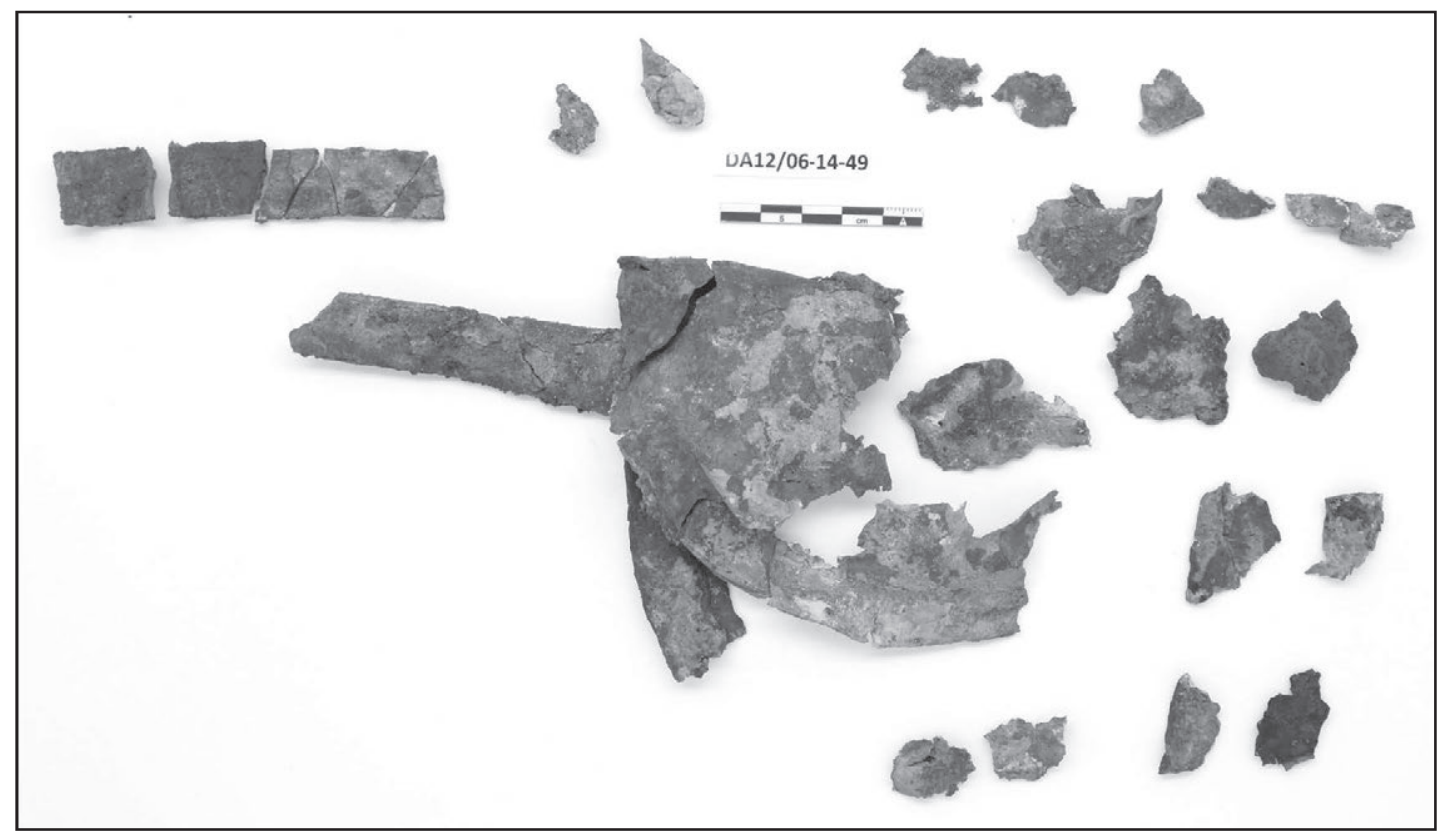

Figura 19. Fragmentos disco cobre. 
ción y el lugar que ocupaban en la necrópolis, los individuos cuyo ajuar eran estas armas, no indican ningún trato diferencial. Esto podría dar respuestas sobre el papel que desempeñaron en la sociedad a su regreso; trayendo a la isla productos e ideas de fuera.

\section{BIBLIOGRAFÍA}

Alexandrescu, A. D. (1980): «La nécropole Gète de Zimnicea». Dacia, N.S. XXIV: 19-126.

Alvarez Jurado-Figueroa, M. y Fernández Martínez, A. (2015): La necrópolis de Son Pellisser (CalviàMallorca), resultados preliminares. Disponible en: http://www.academia.edu/11584545/La necrópolis_de_Son_Pellisser_Calvià-Mallorca_resultados_preliminares

Cabré, M. E. (1934̄a): «El modelo de falcata más típicamente hispánico». Anuario del Cuerpo Facultativo de Archivos, Bibliotecas y Museos, II: 207-212.

Cabré, M. E. (1934b): «Dos tipos genéricos de falcata hispánica». Archivo Español de Arte y Arqueología, X: 207-224.

Cherici, A. (2003): «Armi e società nel Piceno, con una premessa di metodo e una nota sul guerriero di Capestrano». Atti XXII Convegno di Studi Etruschi, Pisa-Roma: 521-531.

Cuadrado Díaz, E. (1989): La panoplia ibérica de El Cigarralejo (Mula, Murcia). Documentos. Serie Arqueología 1. Murcia.

Domínguez Monedero, A. (2005): «Los mercenarios baleáricos». Guerra y Ejército en el Mundo Fenicio-Púnico. XIX Jornadas de Arqueología fenicio-púnica (Ibiza, 2004). Trabajos del Museo Arqueológico de Ibiza y Formentera: 163-189.

Gabaldón Martínez, M. M. (2002-2003): «El trofeo y los rituales de victoria como símbolos del poder en el mundo helenístico». Cuadernos de Prehistoria y Arqueología, 28-29: 127-143. http://dx.doi. org/10.15366/cupauam2003.29.007

Gabaldón Martínez, M. M. (2010): «Sacra loca y armamento: algunas reflexiones en torno a la presencia de armas no funcionales en contextos rituales». Gladius XXX: 191-212. http://dx.doi.org/10.3989/ gladius. 2010.0010

Graells i Fabregat, R. (2014): Mistophoroi ex Iberias. Una aproximación al mercenariado hispano a partir de las evidencias arqueológicas (s. VI - IV a.C.). Venosa: Osanna Edizioni: 51-52.

Guerrero Ayuso, V. M. (1980): «El mercenario balear». Maina 1: 34-40.

Kilian-Dirlmeier, I. (1993): Die Schwerter in Griechenland (ausserhalb der Peloponnes), Bulgarien und Albanien. Prähistorische Bronzefunde IV, 12. Stuttgart.

Nankov, E. (2007): «An ivory scabbard chape from Seuthopolis rediscovered: evidence for a xiphos from early hellenistic Thrace?». Archaeologia Bulgarica XI: 37-46.

Quesada Sanz, F. (1988): «Las acanaladuras de las hojas de las falcatas ibéricas». Cuadernos de Prehistoria y Arqueología, 15: 275-299. http://dx.doi.org/10.15366/cupauam1988.15.009

Quesada Sanz, F. (1992): Arma y Símbolo. La falcata ibérica. Alicante.

Quesada Sanz, F. (1997): El armamento ibérico. Estudio tipológico, geográfico, funcional, social y simbólico de las armas en la Cultura Ibérica (siglos VI-I a.C.) Vol 1-2. Monographies Instrumentum, 3. Ėdition Monique Mergoil. Montagnac.

Quesada Sanz, F. (1999): «Nuevos puñales ibéricos en Andalucía (I). Puñales de frontón». Gladius XIX: 69-96. http://dx.doi.org/10.3989/gladius.1999.14

Stary, P. F. (1981): Zur Eisenzeitlichen Bewaffnung und Kampfesweise in Mittelitalien (ca. 9 bis 6 Jh. V, Chr.). Marburger Studien zur vor-und frügeschichte 3 I-II. Mainz.

Strydonck, M. van, Aramburu, J., Fernández, A., Alvarez, M., Boudin, M., De Mulder, G. (s. f.): Radiocarbon dating of the Son Pellisser lime burial (Calvià, Mallorca). Inédito.

Recibido: 20/07/2015

Aceptado: 05/05/2016 